\title{
Er,Cr:YSGG Laser as a Treatment Option for Operculectomy in Children
}

\author{
Vidyaa Hari lyer
}

\begin{abstract}
Erbium lasers belong to the mid infrared nonionizing part of the electromagnetic spectrum. Erbium family of lasers consists of Er,Cr:YSGG - $2780 \mathrm{~nm}$ wavelength and Er:YAG - 2940 $\mathrm{nm}$ wavelength. These wavelengths are absorbed better by hydroxyapatite and water which are the chromophore in the host tissue. The thick soft tissue covering an erupting tooth is generally treated by conventional surgical excision. Another option available is excision using lasers. Various soft tissue lasers, such as diode laser, have been used for this procedure. A new addition to this generation of lasers is $\mathrm{Er}, \mathrm{Cr}$ :YSGG laser. This article highlights the use of Er,Cr:YSGG in treatment of operculectomy in children. The child did not experience any pain even without the administration of injections, or bleeding during the procedure and was immensely impressed with the excellent healing outcome.
\end{abstract}

Keywords: Erbium laser, Hydrophotonic effect, Painfree dentistry, Pediatric operculectomy procedure.

How to cite this article: Iyer VH. Er,Cr:YSGG Laser as a Treatment Option for Operculectomy in Children. Int J Laser Dent 2014;4(1):39-42.

\section{Source of support: Nil}

Conflict of interest: None declared

\section{INTRODUCTION}

David Payne in 1987 invented the first erbium fiber laser amplifier. In 1988, Hibst and Paghdiwala invented Er:YAG. Since 1995, Erbium families of lasers are available commercially. Er,Cr:YSGG was introduced in 1997 for the surgical needs of clinical dentistry in general practice. The erbium belongs to the rare earth which is embedded in a host crystal. The actual lasing process takes place in the Er ion $\mathrm{Er}^{3+}$. Two host crystals consisting of yttrium, aluminum and garnet $\left(\mathrm{Y}_{3} \mathrm{~A}_{5} \mathrm{O}_{12}\right)$ and yttrium, scandium, gallium and garnet $\left(\mathrm{Y}_{3} \mathrm{Sc}_{2} \mathrm{Ga}_{3} \mathrm{O}_{12}\right)$ are added to the erbium.

Erbium laser energy is absorbed by collagen, hydroxyapatite and water components. It allows the laser to cut

\footnotetext{
Private Practitioner

Fellowship and Diplomate in Laser Dentistry, Smile Dental Clinic, Chennai, Tamil Nadu, India

Corresponding Author: Vidyaa Hari lyer, Private Practitioner Fellowship and Diplomate in Laser Dentistry, Smile Dental Clinic, Chennai, Tamil Nadu, India, Phone: 09840176088 e-mail: vidyaahari@gmail.com
}

soft tissue, tooth structure and bone. In the noncontact mode, the incision is scalpel-like, with very little hemostasis. In contact mode, it performs soft tissue sculpting with adequate hemostasis. The emission mode of the erbium family is free running pulsed in nature with peak power levels of more than 1000 W. Erbiums are the world's most advanced dental laser, which is ideal all-tissue laser because all dental tissues contain water, for the multidisciplinary dentist who performs a broad spectrum of procedures. It delivers the highest level of clinician control, operating efficiency, flexibility in tip and accessory selection. For optimal clinical results and patient comfort in hard and soft tissue procedures, the erbium lasers have set a new standard of clinical performance.

\section{CASE REPORT}

A 7 years old child had visited Smile Dental Clinic, T. Nagar, Chennai, India, with a chief complaint of missing tooth in the upper anterior region. The patient had an adjacent erupted permanent tooth 11 for the last 3 months, and was apprehensive and anxious over the missing tooth 21 (Fig. 1). However, the deciduous teeth 51 and 61 had exfoliated almost at the same time. The eruption pattern for the deciduous teeth was normal. On clinical examination, there was a soft tissue bulge in the area of 21 and was palpable with the digital pressure (Fig. 2). The patient and his parents were anxious to know if there would be further delay in the eruption of 21 . They wanted to know the various

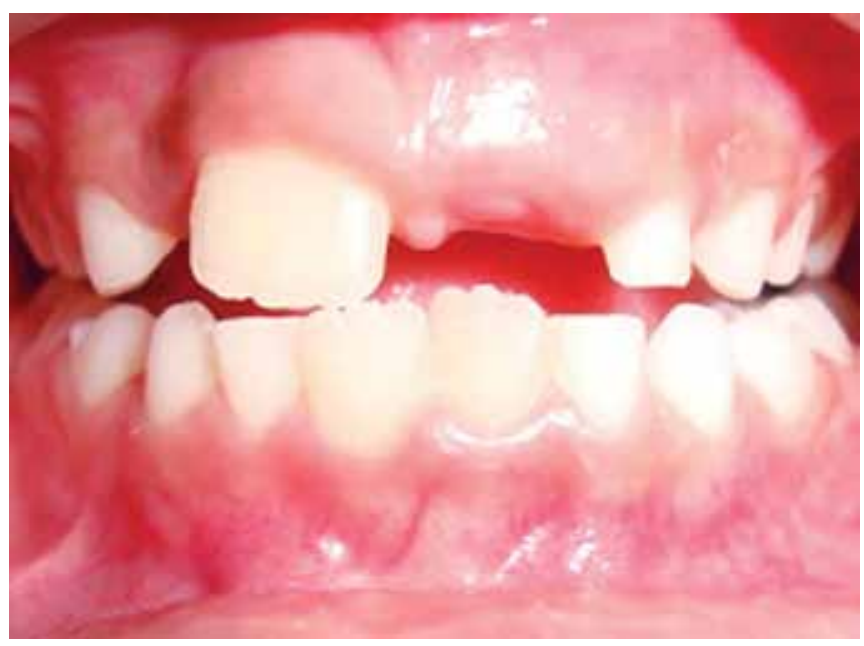

Fig. 1: Preoperative view of unerupted 21 


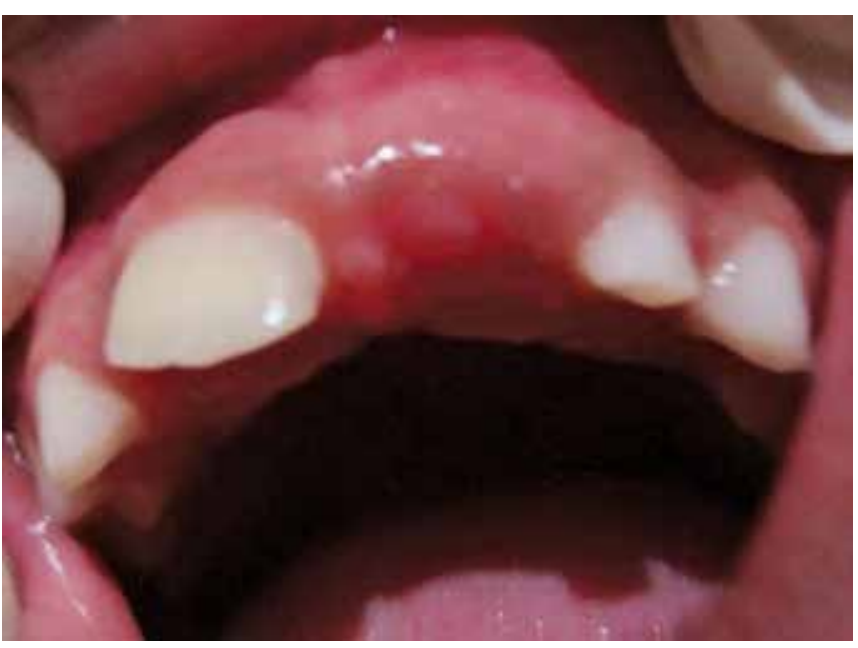

Fig. 2: Thick operculum covering 21 region

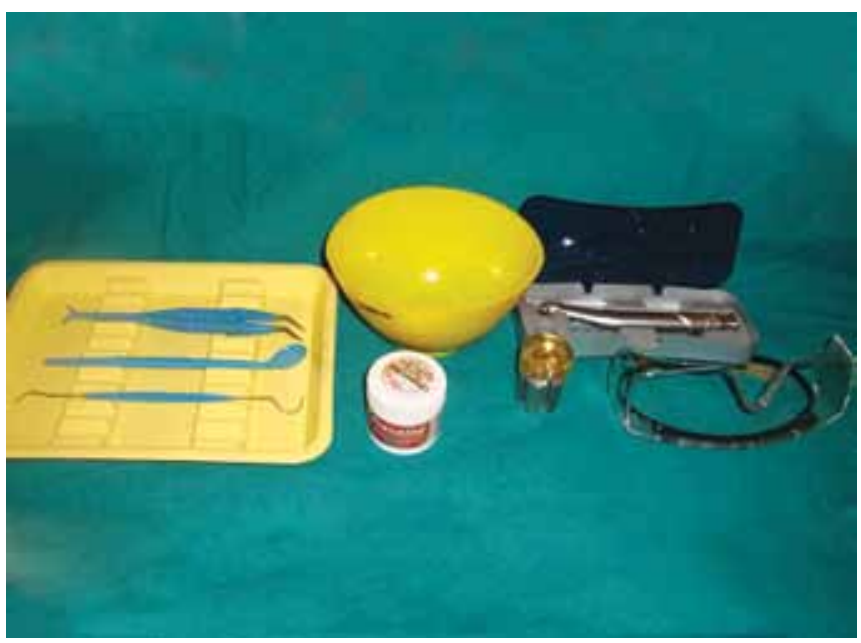

Fig. 4: The instrument set up

options existing and also wanted an immediate comfortable treatment modality for their child. ${ }^{1-3}$ After discussion of the case and the consent taken from the parents, erbium lasers were chosen to excise the operculum due to the various advantages (Table 1).

\section{Laser Equipment}

Er,Cr:YSGG - $2780 \mathrm{~nm}$ wavelength (Fig. 3) — comes under the class IV laser classification with power settings variable from 0.1 to $8.0 \mathrm{~W}$, pulse repetition rates or frequency of 10 to $50 \mathrm{~Hz}$ which can be selected by the clinician, with a pulse duration of $140 \mu \mathrm{sec}$ for $\mathrm{H}$ mode and $700 \mu \mathrm{sec}$ for $\mathrm{S}$ mode, and pulse energy of 0 to $300 \mathrm{~mJ}$. The laser safety officer should ensure all the laser safety protocols (Fig. 4) are met with before the laser is in operation.

\section{PROCEDURE}

The patient and his parents were explained about the procedure in detail. Laser safety protocol was followed and the patient was given a safety glass to wear. No local anesthesia

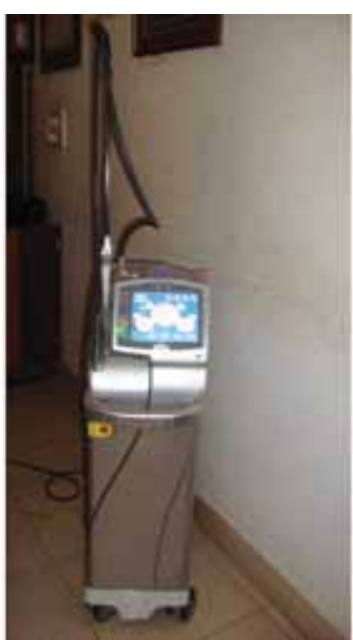

Fig. 3: Er,Cr:YSGG laser

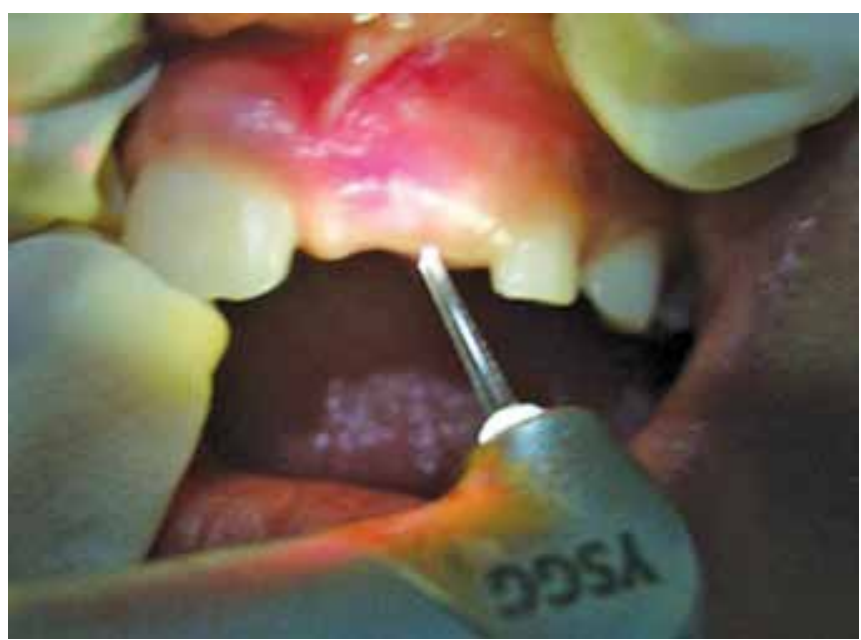

Fig. 5: Er,Cr:YSGG with gold handpiece and sapphire tip being used to remove the operculum

was given, ${ }^{4}$ and operculectomy was done using hard tissue laser. Erbium laser (Fig. 5) with gold hand piece, sapphire chisel tip was used in 21 region, and the pericoronal flap was removed covering the 21 region (Fig. 6). The parameter used was $\mathrm{S}$ mode, $1.5 \mathrm{~W}, 8 \%$ water and $11 \%$ air, $50 \mathrm{~Hz}$ (Fig. 7). The thick pericoronal flap was excised with minimal bleeding (Fig. 8). No suture was necessary. One day (Fig. 9), one week (Fig. 10), and 6-month (Fig. 11) follow-up was done. The tooth had erupted within 6 months to the same level as 11 and brought lot of relief on the patient's face.

\section{DISCUSSION}

The erbium laser wavelength is better absorbed by the chromophore water and hydroxyapatite when compared to melanin and hemoglobin. Water is the important target chromophore and the laser energy from a pulse is absorbed by water within enamel, dentin, bone and soft tissue. The soft tissue has the highest water content, i.e. greater than $70 \%$ which absorbs the energy produced by the Er,Cr:YSGG laser, 


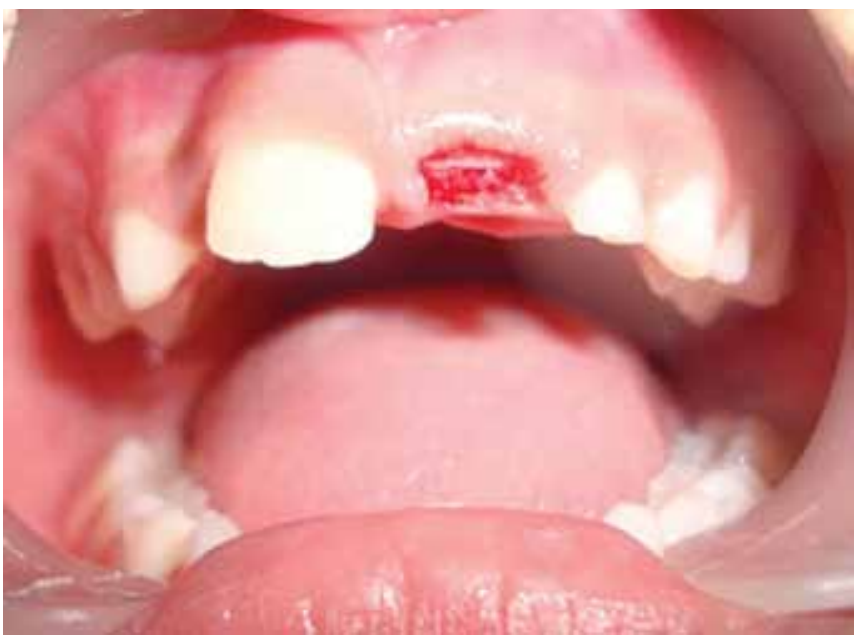

Fig. 6: Immediate postoperative view showing incisal edge of 21

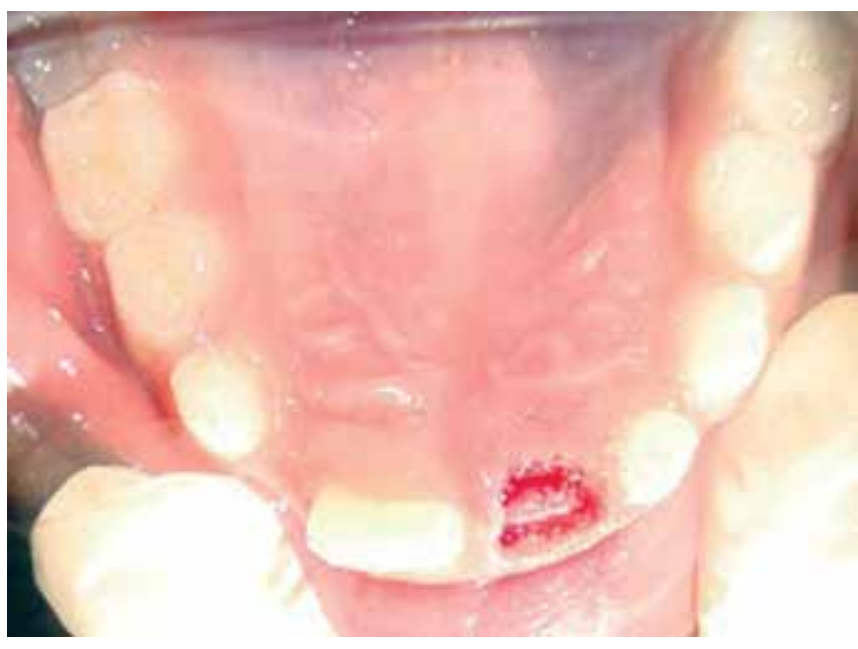

Fig. 8: Occlusal view of 21 exposed

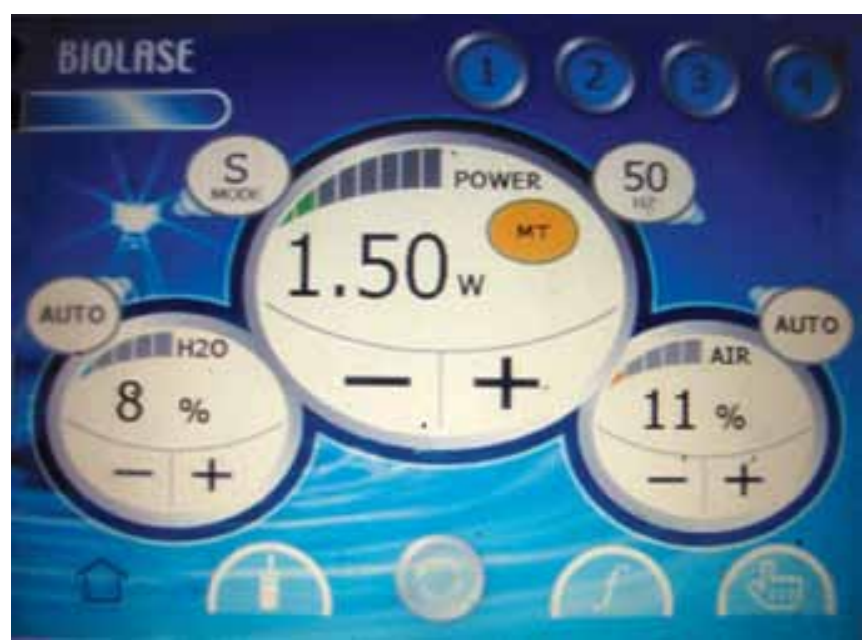

Fig. 7: Laser parameter used in the operculum procedure

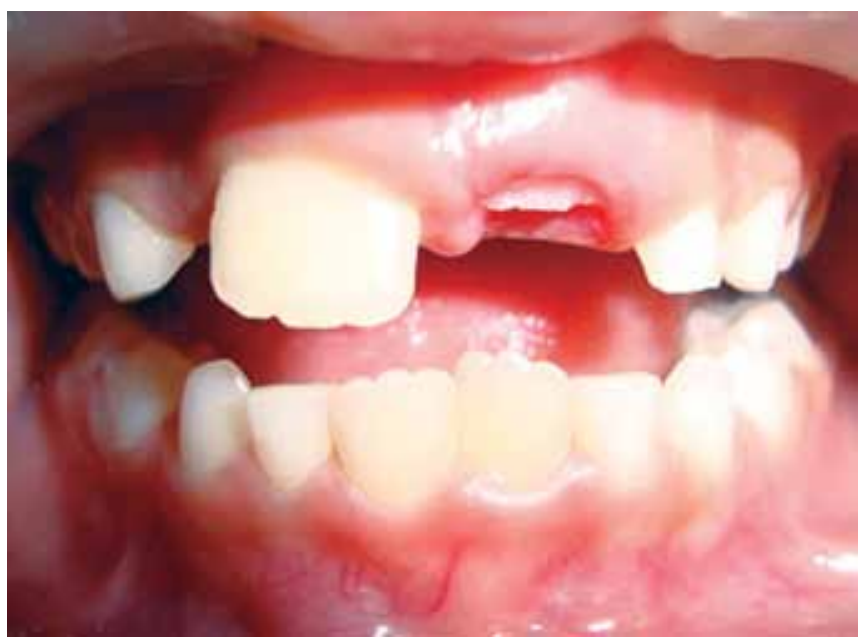

Fig. 9: One day postoperative view showing healed soft tissue

Table 1: Comparing the advantages of erbium vs diode lasers in pediatric patients

Erbium lasers
Erbium lasers have only 2 to 3 cell layer deep effect.

Due to low depth of penetration, the collateral damage is less.

Water being the most important chromophore and readily available, it is easily absorbed bringing about the desired effect.

Bleeding is however reduced and controlled by adjusting the laser parameters.

No anesthesia is necessary due to fast action of the laser.

The child is enamored by the popping sound and painless, relatively fast and comfortable treatment procedure.

and the result is ablation ${ }^{5}$ of the target tissue. This causes a rapid explosive expansion of the water. The interaction of the laser with water and the subsequent effect is known as the hydrophotonic effect. There is no pain as the laser energy is absorbed fast and, hence, no injections are necessary. There is minimal or no thermal damage also. However, the water and air settings in spray should be balanced with laser power, tissue type and type of the tip. $\mathrm{H}$ mode and $\mathrm{S}$ mode

\section{Diode lasers}

Diode lasers work upon 15 to 20 cell layer deep as their depth of penetration is higher.

In diodes, due to higher depth of penetration, the collateral damage is more.

Hemoglobin being the chromophore, the laser energy is absorbed by it and there is no bleeding.

There is relatively a cleaner, bloodless, visible working area.

No anesthesia is necessary as the lasing action is almost comfortable for the child.

The child is in awe of the fact that it is bloodless, comfortable and painless procedure with hassle-free healing period.

can both be used on soft tissue. The long pulse $\mathrm{e}^{6}$ of $\mathrm{S}$ mode provides better hemostasis compared to $\mathrm{H}$ mode. ${ }^{7}$ The main difference is slightly less hemostasis and coagulation effect when compared to diode lasers as the chromophore in diodes is hemoglobin. Coagulation of soft tissue can be achieved by either a long pulse of S mode which is 10 times longer thereby heating up the tissue to accelerate hemostasis or giving more pulses per second which can be to a maximum 


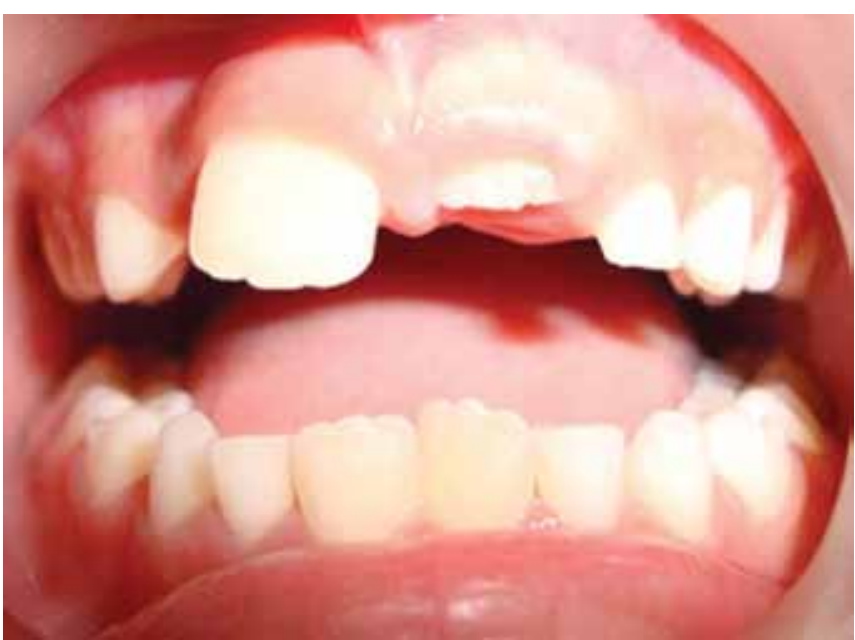

Fig. 10: One week postoperative view showing 21 with mamelons

of $50 \mathrm{~Hz}$. In both the scenarios, the water levels should be low to reduce the cooling effect and aid in hemostasis.

Lasers ${ }^{8-10}$ being end-cutting in nature, focusing and defocusing of the laser energy changes the cutting rates and brings about the desired results. Usually, diode laser being soft tissue lasers are used for soft tissue lesion procedure, but the penetration depth is much higher in diode with collateral damage, hence, erbium lasers were chosen for the treatment. The erbiums have low penetration depth and hence the extent of ablation can also be controlled without causing any untoward collateral damage, especially to the underlying crown of the erupting tooth. It also provides sterile environment at the surgical site and, hence, aids in better healing. ${ }^{11}$ Thus, it is a minimally invasive procedure. ${ }^{12}$ Lasers have emerged as an excellent tool for soft tissue excisional biopsies.

\section{CONCLUSION}

In this case, the patient did not experience any pain and did not require any local anesthetics to be used during the procedure. During the healing process, the patient was very comfortable with no pain and complete healing with no complications was observed. Hence, there was no medication taken by the child. Today, more dentists prefer laser dentistry, especially for their pediatric patients as they are happy with the clinical outcome. Lasers have gained increased clinical versatility and have attracted many patients due to the advantages.

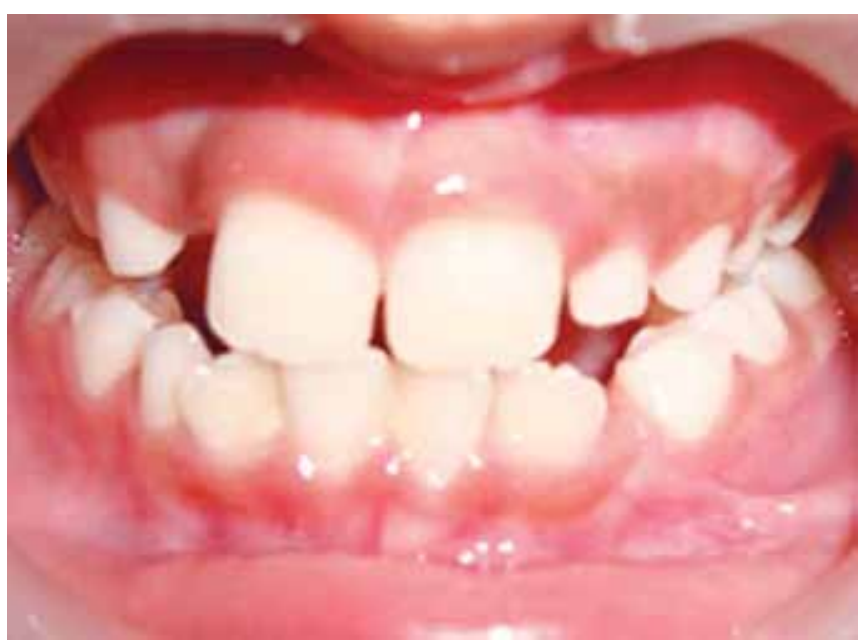

Fig. 11: Twenty-one erupted till the occlusal level of 11

\section{ACKNOWLEDGMENT}

I would like to thank Dr Padmapriya Ramalingam, my Assistant Doctor, for her constant support during the process of this procedure.

\section{REFERENCES}

1. Kotlow LA. Lasers in pediatric dentistry. Dent Clin N Am 2004;48:899-922.

2. Martens LC. Laser-assisted pediatric dentistry: review and outlook. J Oral Laser Appl 2003;3:203-209.

3. Oral health policies 2002-2003. Pediatr Dent 2003;25:54.

4. Jacobson B, Berger J, Kravitz R, Patel P. Laser pediatric crowns performed without anesthesia: a contemporary technique. J Clin Ped Dent 2003;28:11-12.

5. Lizarelli R, Moraiyama LT, Bagnato VS. Ablation rate and micromorphological aspects with $\mathrm{Nd}$ :YAG picosecond pulsed laser on primary teeth. Las Surg Med 2002;31:177-185.

6. Apel C, Franzen R, Meister J, Sarrafzadegan H, Thelen S, Gutknecht N. Influence of the pulse duration of an Er:YAG laser system on the ablation threshold of dental enamel. Lasers Med Sci 2002;17:253-257.

7. Stabholz A, Zeltser R, Sela M, Peretz B, Moshonov J, Ziskind D. The use of lasers in dentistry: principles of operation and clinical application. Compendium 2003;24:811-823.

8. Walsh LJ. The current status of laser applications in dentistry, Aust Dent J 2003;48(3):146-155.

9. White JM, Goodis HE, Horton J, Gold S. Current status of lasers in soft tissue dental surgery. J Periodontal 1994;65(7):733-735.

10. Parkins F. Lasers in pediatric and adolescent dentistry. Dent Clin N Amer 2000;44:821-830.

11. Zeinoun T, Nammour S, Dourav N, Aftimos G, Luomanen M. Myofibroblasts in healing laser excision wounds. Lasers Surg Med 2001;28:74-79.

12. Aoki AA, Sasaki KM, Watanabe H, Ishikawa I. Lasers in nonsurgical periodontal therapy 2004. Periodontal 2000;36:59-97. 